\title{
La Ventanilla Única de Certificación Ambiental en Panamá
}

\section{The only ticket window of environmental certificación in Panama}

Alcides Antúnez Sánchez ${ }^{1}$

Alcibiades Batista Rodríguez ${ }^{2}$

\begin{abstract}
Resumen: $\mid$ En el siglo XXI la modernización del sector público impulsado por el gobierno digital ha desencadenado una serie de aspectos positivos y negativos para los ciudadanos; las reformas innovadoras que ha sufrido el ambiente gubernamental con las políticas de fomento ha sido el gobierno digital. El uso de las Tecnologías de la Informática y las Comunicaciones busca reformar los procesos de gestión pública, vincula a los ciudadanos con la Administración Publica como la herramienta que disminuya la carga burocrática en los trámites, promover la participación ciudadana, fortalecer la confianza en el Estado, viabilizar e incrementar la transparencia y la rendición de cuentas. Su implementación ha traído la modificación de los modelos y políticas de gobierno con una relación jurídica telemática.
\end{abstract}

Palabras Gobierno electrónico, transparencia, eficacia, ciudadanía. clave:

\begin{abstract}
In the century XXI the modernization of the public sector encouraged by the TouchTone Government has triggered a series of positive aspects and negatives for the citizens; The innovative reforms the fact that you have suffered the governmental environment with the policies of fomentation has been the digital government. The use of the Technologies of Information Technology and Communications attempts to reform the processes of public step, links the citizens with the Public Administration like the tool that decrease the bureaucratic load in the steps, promoting the civic participation, strengthening the confidence in the State, viabilizar and incrementing the transparency and accountability. His implementation has brought the modification of the models and governmental policies with a juridical relation telematics.
\end{abstract}

Key

Electronic Government, transparency, efficacy, citizenship.

words:

1.Magister en Asesoría Jurídica. Profesor Auxiliar. Facultad de Ciencias Económicas y Sociales. Universidad de Granma. Cuba. Email: aantunez@udg.co.cu

2. Magister en Administración y Contabilidad. Profesor Contabilidad. Universidad de Panamá. Panamá. Email: arbatista1974@hotmail.com 


\section{Introducción}

En la actualidad se vive en una época de auge de las tecnologías digitales, caracterizadas por constantes cambios e innovaciones científicas y tecnológicas al evolucionar de manera vertiginosa, siendo necesario apropiarse y actualizarse para interactuar con ellas. En el mundo digital, la incursión del gobierno digital ha traído la modificación de los modelos clásicos y las políticas de gobierno de los Estados. Las actividades que los ciudadanos realizan con la Administración Pública se efectúan de forma digital desde finales del siglo XX, suceso que ha avanzado en el siglo XXI en una relación jurídica telemática. ${ }^{1}$

La estrategia E-government en la modernización del sector público en el siglo XXI permite el abastecimiento de información, optimiza los procesos comerciales y facilita la comunicación entre los diferentes niveles del gobierno y el desarrollo de actividades de la Administración Pública con los ciudadanos y las empresas al potenciar los servicios públicos. Los gobiernos han encontrado nuevas maneras que propician la participación más activa de sus ciudadanos, y ayudan a cumplir el mandato constitucional en una democracia transparente. La estrategia innovadora con el uso de internet en la realización de disímiles procesos de comunicación impulsa el gobierno digital. ${ }^{2} \mathrm{Se}$ ejecuta a través de la Ventanilla Única en los Estados que la han implementado. ${ }^{3}$

Material y métodos: Se propone como objetivo caracterizar la Ventanilla Única de Certificación Ambiental dentro de los procesos vinculados al Derecho Administrativo Ambiental dentro del ordenamiento jurídico por el Ministerio del Ambiente para la gestión ambiental como parte de las políticas públicas en el fomento del gobierno digital en Panamá. Para ello se ha realizado esta investigación que permite conocer como el legislador la ha reconocido en el ordenamiento jurídico. Se han utilizado como materiales y métodos: el histórico lógico, el de inducción deducción, el de análisis síntesis, y el de comparación jurídica.

\section{La Ventanilla Única. Origen, concepto, función, evolución y regulación normativa:}

Las Tecnologías de la Informática y las Comunicaciones (Tic) han tenido un desarrollo desde el pasado siglo XX. Evolucionan en el siglo XXI, no solo en mayor capacidad de almacenamiento, radio de alcance, velocidad de transmisión, aplicación o grado de interactividad, son más sofisticadas y aumentan para diversos propósitos no concebidos. Siempre hay nuevas tecnologías, actualizaciones

\footnotetext{
${ }^{1}$ Bernadí Gil, X. (2005) Derecho Público y Administración electrónica: una visión panorámica, Nuevas políticas públicas. Anuario multidisciplinar para la modernización de las Administraciones Públicas, № 1, España; AA. VV. (2004) Administración electrónica y procedimiento administrativo, Ministerio de Economía, Madrid.

${ }^{2}$ Castoldi, P. (2002) El gobierno electrónico como un nuevo paradigma de Administración. Revista Prudentia Juris, № 55 . Buenos Aires.

${ }^{3}$ Cerrillo Martínez, A. (2012) La contribución de las Tic a la mejora de la transparencia administrativa. Revista Arbor Ciencia, Pensamiento y Cultura, Vol. 188, España; Blasco Díaz, J. (2008) Los derechos de los ciudadanos en su relación electrónica con la Administración. Derechos fundamentales y otros estudios, Editorial Justicia de Aragón, Zaragoza; Cierco Seira, C. (2009) Algunas reflexiones sobre la simplificación de los procedimientos administrativos a la luz de los avances de la Administración electrónica, Revista General de Derecho Administrativo, №. 19, España.
} 
y aplicaciones con las que el ciudadano y los servidores públicos interactúan. ${ }^{4}$ La sociedad la denomina "Sociedad de la Información o Sociedad del Conocimiento".

Castell, la identifica como la Sociedad en Red, en coincidencia con Pérez Luño, al reconocer la existencia del ciberespacio como un área para la comunicación, el comercio y la participación ciudadana en donde se evocan nexos con la Ética y el Derecho. ${ }^{5}$

El avance de las Tic ha impactado casi todas las áreas de la actividad humana. Incide en la vida y como sociedad en lo económico, político, social, cultural, educativo, etc., al reconfigurar la forma de percibir el mundo, el comportamiento y la forma de interrelación. ${ }^{6}$ Ello se aprecia con el impulso que ha recibido el principio de simplificación en los últimos años desde el siglo XX con los actos de la Administración Pública, tiene la estrategia de aislar la simplificación con la introducción de medios electrónicos en la gestión administrativa.

La Ventanilla Única (VU) está a la ofensiva contra la complejidad de la tramitación administrativa que concurre entre la Administración Pública/ administrados. Es el reto moderno con el uso de las Tic contra la burocracia administrativa en el siglo XXI. Su origen se desarrolló en el comercio exterior desde finales del siglo XX. ${ }^{7} \mathrm{La}$ comunidad comercial al adoptar la VU ha simplificado la interacción con los organismos de control en frontera al rediseñar todo el aparato del movimiento transfronterizo de mercancías y pasajeros, con el fin de satisfacer las necesidades de empresarios y ciudadanos en los servicios aduanales. ${ }^{8}$

Los países que trabajan por mejorar las "facilidades del comercio" con la VU ponderan su uso en un gobierno abierto. Se vincula con el Derecho Mercantil en la contratación (permisos negociables), los cobros y pagos, la certificación ambiental, la calidad ambiental, el seguro ambiental, el impuesto ambiental, la contabilidad ambiental y la protección a los consumidores. Su concepto se introduce en la Organización Mundial del Comercio (OMC) y en la Declaración Ministerial de Singapur, 1996. La gran mayoría de los acuerdos comerciales buscan como fin que los exportadores e importadores se beneficien de procedimientos ágiles, transparentes y simplificados, que no sustituyan a los aranceles

${ }^{4}$ Dyson Freeman, J. (2000) EI Sol, el genoma e internet. Las tres cosas que revolucionarán el siglo XXI: la energía solar, la ingeniería genética y la comunicación mundial, Editorial Debate, Madrid.

${ }^{5}$ Castells, M. (2005) La era de la información. La sociedad red, Editorial Alianza, Madrid; Pérez Luño, A. (2014) Teledemocracia, ciberciudadania y derechos humanos, Revista Brasilera de Políticas Públicas, №.2, Brasil.

${ }^{6}$ Pérez Luño, A. (2004) ¿Ciberciudadani@o Ciudadani@.Com?, Editorial Gedisa, Barcelona; Robles Morales, J. (2009) Ciudadanía digital: una introducción a un nuevo concepto de ciudadano. Editorial UOC, Barcelona; Prenski, M. (2010) Nativos e Inmigrantes Digitales, Editorial SEK, España; Martínez-Villalva, J. (2014) La cuarta ola de derechos humanos: los derechos digitales, Revista Latinoamericana de Derechos Humanos, México.

${ }^{7}$ Suñé Llinás, E. (2004) La Ventanilla Única Electrónica. Actas del Xo Congreso Iberoamericano de Derecho e Informática. Centro de Estudios en Derecho Informático, Chile; Salazar Solís, L. (2006) Ventanilla única de gobierno electrónico. Colección documentos de trabajo sobre e-Gobierno. Red de Líderes de Gobierno Electrónico de América Latina y El Caribe; Gamero Casado, E. (2009) Ventanilla única y administración electrónica en la transposición de la directiva de servicios, Universidad Pablo de Olavide de Sevilla, España; Castillo Y. (2016) Ventanilla única de trámites-Una aproximación conceptual. Administración y Finanzas. Disponible en: https://www.monografias.com/docs113/ventanilla-unica-tramites-aproximacion-conceptual/ventanilla-unica-tramites-aproximacionconceptual2.shtml

${ }^{8}$ Arena, G. (2004) E-Government y Nuevos Modelos de Administración. Revista de Administración Pública № 163, España; Álamo González, N. (2007) La utilización de las nuevas tecnologías entre las Administraciones públicas y los ciudadanos, REDA, No 133, España; Canals Ametller, D. (2012) Simplificación administrativa y directiva de servicios: objetivos, medios e incidencias, el procedimiento administrativo: descarga burocrática, INAP, España. 
y tarifas que se eliminan. Se implementa en la contratación electrónica, los pagos, y el marketing. La División de Economía y Administración Pública de las Naciones Unidas (2002), señala que “el gobierno electrónico es un compromiso permanente del gobierno para mejorar la relación entre los ciudadanos y la administración pública, mediante el intercambio eficaz y eficiente de servicios, información y conocimiento". 9

La VU en su contextualización comparte información y los usuarios realizan el trámite digital para obtener permisos, autorizaciones y certificaciones para las operaciones de comercio; consultan información sobre los procedimientos de importación y exportación. Es un concepto construido sobre la Recomendación N ${ }^{\circ} .33$ de la ONU de $2005 .{ }^{10}$ En el Centro de las Naciones Unidas para la Facilitación del Comercio y las Transacciones Electrónicas emitió la Recomendación y Directrices para el establecimiento de las VU Comercio Exterior, existen requisitos y costos asociados, para cumplirlos puede constituir un obstáculo en su desarrollo. ${ }^{11}$ La VU permite la información y/o los documentos comerciales se presenten solo una vez y en un único lugar. Mejora el principio de eficacia y rentabilidad de los controles oficiales. Reduce los costos de la Administración Pública/operadores comerciales optimizando recursos. ${ }^{12}$

La Organización de las Naciones Unidas para la Educación, la Ciencia y la Cultura (UNESCO) en su informe "Hacia las Sociedades del Conocimiento" 2005, señala: como concepto tiene dimensiones sociales, éticas y políticas mucho más vastas que la Sociedad de la Información; se refiere a ella en plural debido a que hay una intención de rechazar la unicidad del modelo "listo para su uso" que no tenga suficientemente en cuenta la diversidad cultural y lingüística, elemento que le permite al mundo reconocerse en los cambios que están ocurriendo de modo vertiginoso en el siglo XXI con el fomento de las Tic. ${ }^{13}$

También, en este mismo contexto, la Carta Iberoamericana de Gobierno Electrónico de Chile, 2007 reconoce: El uso de las Tic en los órganos de la Administración para mejorar la información y los servicios ofrecidos a los ciudadanos, orienta la eficacia y eficiencia de la gestión pública e incrementa sustantivamente la transparencia del sector público y la participación de los ciudadanos. ${ }^{14}$ La importancia para América Latina y Caribe que tiene la VU se refleja en el informe del año 2010, Sistema Económico Latinoamericano y del Caribe (SELA) "Ventanillas Únicas de Comercio Exterior (VUCE) en América Latina y el Caribe: avances y retos pendientes". ${ }^{15}$

\footnotetext{
${ }^{9}$ ONU (2012) Estudio sobre Gobierno Electrónico. Departamento de Economía y Asuntos Sociales. New York.

${ }^{10} \mathrm{OMC}$ (2012) Cómo construir un entorno de ventanilla única. Vol. 1. Guía Ejecutiva OMC. New York.

${ }^{11}$ CEFACT/ONU (2005) Recomendaciones y Directrices para el Establecimiento de una ventanilla única. United Nations Publications. Ginebra.

${ }^{12}$ CLAD-ONU (2007) Carta Iberoamericana de Gobierno Electrónico. Chile.

${ }^{13}$ UNESCO (2005) Hacia las sociedades del conocimiento. Informe Mundial, Paris.

${ }^{14}$ Piana, R. (2010) La Carta Iberoamericana de Gobierno Electrónico. Orientaciones y buenas prácticas. Democracia Electrónica. Universidad de Zaragoza. España.

${ }^{15}$ UNESCO (2013) Enfoques Estratégicos sobre las TICS en América Latina y el Caribe. Oficina Regional de Educación para América Latina y el Caribe, Santiago de Chile.
} 
Otro impacto en este estudio de las Tic en su aplicación ha sido en la economía digital a través de la infraestructura de Internet y las potencialidades de las tecnologías como el Cloud computing, Big Data, Internet de las Cosas (IoE), Smart Cities, Industria 4.0. Elementos articulados desde un enfoque interdisciplinario y transdisciplinario en las Ciencias Empresariales, Educación, Ciencias Jurídicas, Ciencias Contables; este se considera es el primer contacto con lo tecnológico en el sector empresarial industrial. ${ }^{16}$

La ONU señala en este sentido, que el gobierno electrónico es un pilar en la construcción de un marco estratégico de desarrollo sostenible para los Estados. Puede ser la clave para alcanzar la integración de las metas económicas, sociales y ambientales en el siglo XXI como principio del Derecho Ambiental. En la medida que el sector público reforme las instituciones y los procesos estructurales para aumentar la eficacia y mejorar la prestación de servicios dentro del E-Goverment se creará un ambiente propicio para los negocios, y ofrecerá más oportunidades de participación a la ciudadanía. Se convertirá en el ente clave del desarrollo sostenible. ${ }^{17}$

Para la ONU el objetivo del gobierno electrónico es establecer mejores procesos y sistemas con mayor eficacia, efectividad, inclusión y sostenibilidad por las Administraciones Públicas/ ciudadanía. La UNESCO ha reclamado a los Estados que presten especial interés en lograr un mayor acceso a la información de dominio público mundial; para ello es necesario concebir estrategias que superen los obstáculos económicos y potencien el derecho a la comunicación y al reconocimiento de la información, la utilización eficaz de las telecomunicaciones y la información en educación, ciencia y cultura. ${ }^{18}$

El gobierno electrónico en este estudio se aprecia que con su fomento mejora cualitativamente los servicios e información que se ofrece a los ciudadanos, aumenta la eficiencia y eficacia de la gestión pública dentro de sus principios de actuación; incrementa la transparencia del sector público y la participación ciudadana. ${ }^{19} \mathrm{Su}$ desarrollo constituye otra forma de entender el cambio institucional, donde las capacidades estatales conforman los recursos necesarios para llevar adelante una administración de tipo electrónica-relacional. La interoperabilidad en la Administración Pública se manifiesta en diferentes enfoques de relaciones con los administrados, como el G2G: gobierno a gobierno, G2C: gobierno a ciudadano y G2B: gobierno a empresa.

\footnotetext{
${ }^{16}$ Antúnez Sánchez, A. (2018) La formación ambiental mediada por el uso de las Tic. Repensando la innovación educativa, Editorial Universidad de Valencia, España; Procedia Cirp (2014) Industry 4.0. The new industrial revolution. How Europe will succeed. Hg V Roland Berg. Strategy Consult. GmbH, Münich; Tascón, M. (2013) Big Data: Pasado, presente y futuro. Editorial Telos. España; Pintos, C. (2012) Open Data, reutilización de la información pública para crear una nueva empresa, Editorial Netbiblo, España; Fernández Aller, C. (2012) Algunos retos de la protección de Datos en la sociedad del conocimiento. Especial detenimiento en la computación en nube (cloud computing), Revista de Derecho UNED, №. 10, España.

${ }^{17}$ Piana, R. (2010) La Carta Iberoamericana de Gobierno Electrónico. Orientaciones y buenas prácticas. Democracia Electrónica. Universidad de Zaragoza. España.

${ }^{18}$ Cfr. UNESCO (2013) Enfoques Estratégicos sobre las TICS en América Latina y el Caribe. Chile.

${ }^{19} \mathrm{ONU}$ (2012) Estudio sobre Gobierno Electrónico. Departamento de Economía y Asuntos Sociales. Nueva York.
} 
Suñe Llinas, considera desde su postura que el Derecho Informático tiene una vertiente de aplicaciones teleinformáticas de directa relevancia para las organizaciones jurídicas (Informática Jurídica) y otra dimensión de Derecho que recae tanto sobre objetos teleinformáticos, como de las cuestiones sociales características de la sociedad de la información. El E-Goverment tiene un marco interdisciplinar, donde se abordan de forma conjunta e integrada cuestiones que son tanto de Informática Jurídica (aplicaciones) como de Derecho de la Informática (Derecho). ${ }^{20}$

Galván Ruiz \& García López, coligen que la Administración Electrónica es tan antigua como la informática misma. Se evidencia con la primera mecanización preinformática, las máquinas mecánicas que tabulaban tarjetas perforadas. Se desarrolló para la elaboración del censo en los Estados Unidos de América en 1890 para la estadística pública. Las Tic se desarrollan en sus inicios con el servicio de la administración militar en la década de los 60 ' del siglo pasado. ${ }^{21}$

Sáez Vacas, refiere "Las tecnologías de la información son el último eslabón de la cadena de inventos humanos que va desde el lenguaje hablado, la escritura y la imprenta, hasta nuestros días. El ser humano inventa una tecnología, sea un instrumento material, sea conceptual, y está de vuelta, lo transforma a él". 22

Delpiazzo, describe desde su postura que el gobierno electrónico es un aspecto genérico que comprende la administración electrónica (e-A) y la democracia electrónica (e-D), siendo básicamente la prestación de servicios públicos y el acceso a los mismos a través de las Tic. ${ }^{23}$

La Comisión Económica para América Latina y el Caribe (CEPAL) reconoce que las Tic han favorecido la comunicación instantánea y la globalización. Estar dentro de la red significa estar vinculado desde cualquier lugar del mundo con todos los otros. La diferencia de latitudes y longitudes se anula en el tiempo de la comunicación. Los bienes que de ella se derivan son elementos claves para el desarrollo de un país, donde la economía mundial es digital. ${ }^{24}$

Ahora, se justiprecia, que con la diversidad de conceptos de qué entender por gobierno electrónico y donde se debe aplicar para avanzar hacia la democracia digital, donde todos estos conceptos hacen referencia a una nueva relación, transformada en positivo, entre el Estado/ciudadanos, siendo el gobierno electrónico quien rediseña la gestión pública para mejorar la prestación de servicios al ciudadano como mediador en el uso de las tecnologías. La revolución de las Tic y la evolución

\footnotetext{
${ }^{20}$ Suñe Llinas, E. (2000) Tratado de Derecho Informático. Introducción y Protección de datos personales, 1ª edición, Editorial Universidad Complutense de Madrid, España; Suñé Llinás, E. (2016) ¿Tres o cuatro generaciones de Derechos Humanos? Aporte de claridad conceptual a una feliz ocurrencia. Los Derechos Humanos en el siglo XXI. Editorial Porrúa, México; Suñe Llinas, E. (2016) Derecho informático de las cosas o de segunda generación: El Derecho de la Informática en la $4^{a}$ Revolución Industrial o de la Productividad, Revista Ambiente Jurídico, №. 19, Colombia.

${ }^{21}$ Galván Ruiz, J. \& García López, P. (2007) La Administración Electrónica en España. Editorial Ariel, España.

${ }^{22}$ Sáez Vacas, F. (2007) Propuesta personal, basada en la SocioTecnología de la Información y la Cultura: Conviene desarrollar una inteligencia Tecnosocial. Revista Telos, $\mathrm{N}^{\circ}$. 73, España.

${ }^{23}$ Delpiazzo, C. (2002) Oportunidades y obstáculos del e-commerce, Anuario Derecho Informático, F.C.U. Montevideo; Delpiazzo, C. (2005) Derecho y nuevas tecnologías de la información en los umbrales del siglo XXI, Anuario Derecho Informático, F.C.U. Montevideo.

${ }^{24}$ CEPAL (2018) $6{ }^{\text {ta }}$ Conferencia Ministerial sobre la Sociedad de la Información de América Latina y el Caribe: Agenda Digital para América Latina y el Caribe (eLAC2020).
} 
demográfica (urbanización) están descentralizando las estructuras burocráticas de los Estados con mayor participación en la gobernanza de los asuntos públicos. ${ }^{25}$

\section{Reconocimiento y tratamiento jurídico del uso de las Tic}

En los ordenamientos jurídicos, se aprecia como los Estados han regulado esta relación jurídica telemática con la Ley de Acceso a la Información Pública, piedra angular de la democracia digital para garantizar un mínimo control de los ciudadanos sobre la acción de sus gobernantes mediante el acceso a la información que el poder político maneja, la que guarda relación con el Bid Data regulado en la Ley de Datos. ${ }^{26}$

El tratamiento en la Unión Europea se constata como esta regulación jurídica aparece en la Ley de Acceso Electrónico de los Ciudadanos a los Servicios Públicos. En España, el Derecho Autonómico está a favor de la consolidación el principio de simplificación transversal de la actuación de la Administración Pública con los ciudadanos, al decir de Gamero Casado, Valero Torrijos, Piñar Mañas, Barnes Vázquez, Bernardí Gil y Palomar Olmeda. ${ }^{27}$

En América Latina y el Caribe, la Declaración de Santo Domingo sobre Gobernabilidad y Desarrollo en la Sociedad del Conocimiento de la Organización de Estados Americanos, acentúa la importancia de las Tic como herramienta transversal para el logro del desarrollo equitativo y sostenible para fortalecer la gobernabilidad. El compromiso de los Estados miembros es incorporar las Tic en sus planes de desarrollo y en la modernización para propiciar eficiencia en la gestión y provisión de servicios en el sector público a través de estrategias de gobierno electrónico para mejorar la información a la población. ${ }^{28}$

La digitalización de la información permite crear nuevas formas de codificación, representación y construcción de la cultura en las que las experiencias analógicas a menudo se confunden con las virtuales, propiciando una ida y vuelta entre estos dos escenarios de interacción sociocultural, evidencian la influencia de los medios de comunicación no ha ido a la par del fomento de la alfabetización digital. ${ }^{29}$ El gobierno electrónico impacta en la transparencia de la gestión pública.

\footnotetext{
${ }^{25}$ Cfr. Organización de Naciones Unidas (2012) Estudio sobre Gobierno Electrónico. New York.

${ }^{26}$ Martín Delgado, I. (2009) Naturaleza, concepto y régimen jurídico de la actuación administrativa automatizada, RAP, N ${ }^{\circ}$. 180, España; Oliver Cuello, R. (2009) La regulación de la administración electrónica tributaria, Administración Electrónica Tributaria, Editorial Bosch, Barcelona; Mira Ros, C. (2010) El expediente judicial electrónico, Editorial Dykinson, Madrid.

${ }^{27}$ Gamero Casado, V. \& Valero Torrijos, J. (2009) Ventanilla Única y Administración Electrónica en la transposición de la Directiva de Servicios, 2 $2^{\mathrm{a}}$ edición, Universidad Pablo de Olavide; Barnés Vázquez, J. (2000) Una reflexión introductoria sobre el Derecho Administrativo y la Administración Pública de la Sociedad de la información y del conocimiento, Revista Andaluza de Administración Pública, № 40, España; Palomar Olmeda, A. (2007) La actividad administrativa efectuada por medios electrónicos, Navarra; Bernadí Gil, X. (2005) Derecho Público y Administración electrónica: una visión panorámica. Nuevas políticas públicas. Anuario multidisciplinar para la modernización de las Administraciones Públicas, № 1, España.

${ }^{28}$ Criado, J. (2009) Gobierno electrónico en Latinoamérica: Aproximación desde una perspectiva intergubernamental, Estado, Gobierno, Gestión Pública. Revista Chilena de Administración Pública, No. 14, Chile; CEPAL/ONU (2007) Libro Blanco de Interoperabilidad de Gobierno Electrónico para América Latina y el Caribe. Versión 3.0. United Nations Publications. Ginebra; OMC (2015) Revisión y análisis de la aplicación del Acuerdo de la Organización Mundial del Comercio (OMC) sobre Facilitación del Comercio en Países de América Latina y el Caribe (ALC), SELA, Venezuela.

${ }^{29}$ Rivero Ortega, R. (2007) El Expediente Administrativo. De los Legajos a los Soportes Electrónicos. Editorial Thomson-Aranzadi. Navarra; Ugalde, V. (2004) Sobre la digitalización de trámites en la transición al e-gobierno, Revista Gestión y Política Pública, № 1 , España, pp. 41-80.
} 
"Transparencia, en términos generales, significa conducir las actividades de una manera en que las decisiones, las reglas y otra información se hacen visibles desde el exterior". ${ }^{30}$

Para hacerlo operativo y contrastable se plantea: “...la transparencia en la sociedad de nuestros días significa información fácilmente accesible, fiable, que sea relevante para las decisiones, que resulte comparable y que se presente de forma clara y oportuna. En definitiva, que cumpla los requisitos y características cualitativas del marco conceptual de la contabilidad, con un especial énfasis en la accesibilidad, derivado del papel revolucionario del internet..." 31

Este tema exige a la Administración Pública con el E-Goverment requisitos que tienen que ponderar la seguridad técnica y jurídica. Se instituye en la Ley de Procedimiento de la Administración Pública y la Ley de la Firma Electrónica, incidente en el tratamiento de los datos de los ciudadanos. Guarda relación con el Derecho Laboral (Teletrabajo) ${ }^{32}$, con el Derecho Marítimo (digitalización de las actividades en puertos, navegación y aduanas). En la Votación Electrónica (E-vote), primer escalón de la Democracia-E, como lo refieren Arena, Cruz Rivero, Cotino Hueso, Barriuso Ruiz, y Blasco Díaz. ${ }^{33}$ Otro elemento a ponderar en este artículo es el uso es el de dinero electrónico (Bitcoin) al cambiar las relaciones monetario mercantil. ${ }^{34}$

Permite justipreciar que la interacción entre las Tic y la gestión de la Administración Pública, así como al proceso de las políticas públicas constituye uno de los pilares básicos en el campo de acción del E-gobierno, contextualizada en el liderazgo, el capital humano, el diseño y cambio organizativo, las relaciones interadministrativas e intergubernamentales, la comunicación y el marketing de los servicios y la transparencia, en un entorno en el que las Administraciones Públicas son usuarias de las Tic. En su tratamiento se pondera el cumplimiento del principio de información y se está en presencia de tópicos de descarga burocrática y simplificación de la intervención administrativa sobre la actividad de los particulares y personas jurídicas con acato al principio de legalidad.

Hoy se aprecia que el paradigma papel hoy convive con el paradigma digital, gestionado en sistemas híbridos de información. La documentación en papel puede ser convertida con facilidad en objetos digitales derivados y ser gestionados para su preservación y acceso como mismo sucede con los objetos digitales originarios al ser parte del patrimonio digital. Facilitan la vida de la comunidad al

\footnotetext{
${ }^{30} \mathrm{Hood}$, C. (2010) ¿Accountability and Transparency: Siamese Twins, Matching Parts, Awkward Couple? West European Politics, № 5 , pp.989-1009; Leal, B. (2016) Planificación, colaboración y autocontrol: nuevos instrumentos normativos para la administración fiscalizadora. Revista de Derecho Público, №. 83, Chile, pp. 105-122; Junceda Moreno, J. (2016) Obligaciones sobre transparencia. Protección de datos. Sobre los límites de la transparencia en el ámbito local. La Administración Práctica, № . 8, España. pp. 55-61.

${ }^{31}$ Montesinos, V. (2009) Transparencia y responsabilidad en el sector público: el papel de la información en tiempos de crisis. Revista AECA N ${ }^{\circ} .87$, España, pp.26-28.

${ }^{32}$ Ortiz Chaparro, F. (1995) El Teletrabajo. Una Nueva Sociedad Laboral en la Era de la Tecnología. Editorial McGraw \& Hill. España; Antúnez Sánchez, A. (2008) El teletrabajo en Cuba. №. 51. Revista Federal del Trabajo, Argentina.

${ }^{33}$ Arena, G. (2004) E-Government y Nuevos Modelos de Administración. Revista de Administración Pública № 163, España; Cruz Rivero, D. (2006) El DNI Electrónico y el Mercado de las Entidades de Certificación. Revista de Contratación Electrónica. № 69, España; Cotino Hueso, L. (2006) El Voto Electrónico o la Casa por el Tejado. La Necesidad de Construir la Democracia y Participación Electrónicas por los Cimientos. Libertades, Democracia y Gobierno Electrónicos. Editorial Comares, Granada; Barriuso Ruiz, C. (2007) Administración electrónica, Editorial Dykinson, Madrid; Blasco Díaz, J. (2008) Los derechos de los ciudadanos en su relación electrónica con la Administración. Derechos fundamentales y otros estudios, Editorial Justicia de Aragón, Zaragoza.

${ }^{34}$ Martino, A. (2015) Sociocibérnetica, Informática Jurídica e Infoética. Buenas prácticas y lecciones aprendidas. Editorial UNIJURIS, Cuba.
} 
constituir ahorros en los gastos públicos y permitir el aumento de la eficiencia y la transparencia en la gestión Administración Pública/ ciudadanos/empresarios (Ventanilla Única Empresarial). ${ }^{35}$

\section{La Ventanilla Única. Definición, función, contenido, aplicación, clasificación, y naturaleza jurídica:}

La VU es un instrumento unitario e integral para satisfacer de manera plena a los usuarios. No es un instrumento funcional, es un mecanismo visual para el usuario que pretende identificarle como interlocutor único con el que realiza los trámites digitales que precise y al que solicite la información que necesite, de aquí su naturaleza jurídica. A pesar de tratarse de un instrumento de información por vía telemática (constituye el nivel primario o elemental de administración electrónica) articulado en un Centro Único de Información, soportado en un sistema de información y tramitación. ${ }^{36}$ Su función es definida:

-Una aplicación de los conceptos de facilitación del comercio para reducir los obstáculos no arancelarios.

-Es un servicio que permite a los operadores comerciales presentar la información y documentos en un solo punto de entrada a fin de satisfacer los requisitos normativos relacionados con la importación, exportación y el tránsito. Si la información es electrónica, los elementos de datos específicos solo se deberían presentar una vez. No implica, la aplicación y el uso de Tic sofisticadas, aunque el servicio mejora si los gobiernos se identifican e implementan las tecnologías. ${ }^{37}$

Los Estados han fomentado medidas para simplificar los actos administrativos con las herramientas que aportan las Tic en una arquitectura digital eficiente con la VU. Un ejemplo de lo narrado aparecen en instrumentos en la Unión Europea con el "Libro Verde Menos trámites administrativos para los ciudadanos: promover la libre circulación de los documentos públicos y el reconocimiento de los efectos de los certificados de estado civil (2010)"38, al ponderar el principio de celeridad. Sin menoscabar otros principios informadores del proceso de simplificación y racionalización de los procedimientos que persigue su implementación: eficacia, eficiencia, economía procedimental, transparencia administrativa y servicio efectivo a los ciudadanos. ${ }^{39}$

\footnotetext{
${ }^{35}$ Gamero Casado, E. (2009) Interoperabilidad y administración electrónica: conéctense, por favor, RAP, № 179, España, pp.291 y ss; Cerrillo Martínez, A. (2008) La Ley de Administración electrónica. Comentario sistemático a la Ley 11/2007, de 22 de junio, de acceso electrónico de los ciudadanos a los Servicios Públicos, Editorial Aranzadi, Navarra.

${ }^{36}$ Cfr. Suñé Llinás, E. (2004) La Ventanilla Única Electrónica. Actas del X Congreso Iberoamericano de Derecho e Informática. Centro de Estudios en Derecho Informático, Chile.

${ }^{37}$ Salazar Solís, L. (2006) Ventanilla Única de gobierno electrónico. Colección documentos de trabajo sobre e-Gobierno. Red de Líderes de Gobierno Electrónico de América Latina y El Caribe. Chile.

${ }^{38}$ Comisión Europea (2010) Libro Verde. Menos trámites administrativos para los ciudadanos: promover la libre circulación de los documentos públicos y el reconocimiento de los efectos de los certificados de estado civil, Bruselas.

${ }^{39}$ Valero Torrijos, J. (2000) Administración Pública, ciudadanos y nuevas tecnologías. El Derecho Administrativo en el umbral del siglo XXI. Editorial Tirant lo Blanch, Valencia; Sancho Royo, D. (2005) Sociedad de la información y gobierno, Instituto Andaluz de Administración Pública, Sevilla; Montesinos, V. (2009) Transparencia y responsabilidad en el sector público: el papel de la información en tiempos de crisis. Revista AECA No.87, España, pp.26-28; Robles Morales, J. (2009) Ciudadanía digital: una introducción a un nuevo concepto de ciudadano. Editorial UOC, Barcelona; Pérez Luño, A. (2014) Teledemocracia, ciberciudadania y derechos humanos, Revista Brasilera de Políticas Públicas, №.2, Brasil.
} 
Su fomento e implementación facilita los trámites al ciudadano, al colocar en una plataforma digital los datos abiertos para mejorar la gestión pública en la modernización del Estado en el siglo XXI, al aumentar la integridad pública, la transparencia, la rendición de cuentas y la participación ciudadana con eficacia. Es un instrumento funcional. ${ }^{40}$

Al estudiar a Cancino Gómez, Witker y Trejo Vargas, en sus aportes sobre el tema, consideran que la VU en el comercio exterior su fin es reducir el tiempo de trámite, abaratar costos y acotar nichos de poder, faculta y determina quiénes operarán la infraestructura tecnológica para que existan procesos horizontales con trámites en tiempo y forma, define el esquema electrónico avalado por las organizaciones internacionales de tal forma que permita a los comerciantes presentar la documentación y/o información exigidas para la importación, la exportación o el tránsito de mercancías en un punto de entrada único. $\mathrm{Su}$ reconocimiento parte de acuerdos de la OMC en materia de Aduanas de 1988 y se desarrolla en los ordenamientos jurídicos internos. ${ }^{41}$

La CEPAL señala que los contenidos de funcionalidad vinculados a la implementación de la VU (el suministro de información administrativa general) son relativamente fácil de articular en la arquitectura donde se diseñe. Supone la necesidad de inventariar los trámites que exige el inicio de una actividad de servicios por la Administración Pública, recopila para ello la información mediante herramientas estandarizada, articulada para su integración en un solo portal de Internet para descargar la información mediante un simple cribado o screening. ${ }^{42}$

Su clasificación tiene tres criterios: ventanillas informativas, de punto de enlace, y transaccionales en la modalidad física y electrónica. Su evolución en el siglo XXI está siendo fomentada a través de aplicaciones (APK) en los móviles inteligentes (M-Government), es la tecnología personal más extendida y de más rápida difusión de la información entre los ciudadanos con el uso de los celulares. Tiene la ventaja de ser una tecnología vinculada a la persona, facilita la verificación de la identidad y localización del que la usa, abre más posibilidades de personalización de los servicios públicos que presta. Su uso ha influido en la democratización del acceso a Internet y el incremento del número de usuarios y dispositivos conectados. Los pequeños ordenadores de mano se comunican y conectaa a Internet. Esta revolución de móviles conectados ha sido posible gracias a los avances realizados en el campo de la miniaturización de la informática. Ha extendido la posibilidad de crear

${ }^{40}$ Cfr. Gamero Casado, E. (2009) Ventanilla Única y administración electrónica en la transposición de la directiva de servicios, Sevilla. ${ }^{41}$ Cancino Gómez, R. (2015) Análisis jurídico de la Ventanilla Única de comercio exterior, Revista Jurídica UNAM, México; Trejo Vargas, P. (2012) Naturaleza del acto administrativo y del despacho aduanero electrónicos o digitales, México y el comercio exterior, Revista Novum, México; Witker, J. (2010) Régimen jurídico del comercio exterior, Editorial MPc, México, p. 124.

${ }^{42}$ CEPAL (2018) $6^{\text {ta }}$ Conferencia Ministerial sobre la Sociedad de la Información de América Latina y el Caribe: Agenda Digital para América Latina y el Caribe (eLAC2020, Chile); Naser. A. et al. (2011) El gobierno electrónico en la gestión pública, CEPAL, Chile; ONU (2012) Estudio de las Naciones Unidas sobre el Gobierno Electrónico, Nueva York. 
objetos con capacidades para incrementar usuarios y dispositivos conectados, y crecer en los datos que se generan. ${ }^{43}$

En este análisis se pondera que el reconocimiento jurídico dentro del Derecho Ambiental de la Ventanilla Única de Certificación Ambiental en el E-Goverment está vinculada al principio 10 de la Declaración de Río sobre el Medio Ambiente y el Desarrollo de 1992, información ambiental. Este es su nexo vinculante.

\section{La Ventanilla Única de Certificación Ambiental}

Un primer acercamiento al tema ambiental en este estudio, se analiza a partir de la postura de Canals Ametller, quien refiere que la tramitación por medios electrónicos tiene como ventajas evitar el exceso de trámites, reducir la carga documental y el factor tiempo en los procedimientos administrativos (tanto para los interesados como para los órganos administrativos), así como la racionalización administrativa, pero no es, un medio de simplificación administrativa sino más bien un mecanismo cuya aplicación práctica permite obtener esas ventajas. ${ }^{44}$

Ni los mercados financieros, ni la sanidad, ni la educación, ni las relaciones entre las empresas serían como son, pero poco sabemos de cómo serán en el futuro. Una de las pocas certezas que tenemos en relación con la administración electrónica es que acabará determinando los modos de relación de los ciudadanos con las instituciones públicas de una manera radicalmente distinta a como son hoy y sin duda, alterando de forma profunda el sistema de derechos, garantías y obligaciones de unos y otras. Uno de los últimos impulsos en esta materia ha sido la Ley de Acceso Electrónico de los ciudadanos a los servicios públicos. ${ }^{45}$

En el Derecho Ambiental Europeo, se pondera dentro de la gestión ambiental integrada en la modernización de la gestión pública la inclusión de la Evaluación Ambiental Estratégica al usar para ello las Tic. Aquí hay una amplia gama de instrumentos de gestión ambiental como los de planificación, promoción, prevención, control, corrección, información, financiamiento, participación, fiscalización, ordenamiento territorial, estándares de calidad ambiental, límites máximos permisibles, certificación ambiental, plan de prevención, etc. La implementación de la VU en los tramites ambientales debe ser accesible los 7 días de la semana de las 24 horas del día.

La implementación por la Administración Pública de la Ventanilla Única de Certificación Ambiental (VUCA) permite una relación jurídica telemática dentro del gobierno digital abierto en materia de protección ambiental ${ }^{46}$ como una nueva relación jurídica. El fin de la VUCA es ayudar al prestador

\footnotetext{
${ }^{43}$ Rossel, P. et al. (2006) Mobile' E-government Options: Between Technology-driven and User-centric. The Electronic Journal of Egovernment, $\mathrm{N}^{\circ} .2$, pp. 79-86.

${ }^{44}$ Cfr. Canals Ametller, D. (2012) Simplificación administrativa y directiva de servicios: objetivos, medios e incidencias, el procedimiento administrativo: descarga burocrática, INAP, España.

${ }^{45}$ Guillén Caramés, J. (2010) La Administración Electrónica: ¿Mito o realidad para los ciudadanos del siglo XXI?, Centro PwC \& IE del Sector Público, Madrid.

${ }^{46}$ Antúnez Sánchez, A. (2018) La fórmula estimulación/recompensa en el Derecho Administrativo Ambiental. Visión desde la administración estratégica por los sujetos de gestión. Revista de Investigación y Análisis De Jure, México.
} 
de servicios ya sea como autoridad directamente competente para expedir los documentos necesarios para acceder a una actividad de servicios, y a sea como intermediario entre el prestador y dichas autoridades directamente competentes. El E-goverment, regulado en Ley №. 11 de 2007 reconoce como principio general al que ha de ajustarse la utilización de las Tic el principio general de simplificación administrativa por el que se reduzcan de manera sustancial los tiempos y plazos de los procedimientos administrativos, logrando una mayor eficacia y eficiencia en la actividad administrativa. ${ }^{47}$

En América Latina y el Caribe es reconocida en los ordenamientos jurídicos vinculada con las herramientas de gestión ambiental en procesos de Evaluación de Impacto Ambiental (EIA), como se aprecia sigue la idea de la Unión Europea en la gestión ambiental. ${ }^{48}$ La VUCA es un mecanismo electrónico creado por la Administración Pública para el desarrollo de los procedimientos de certificación ambiental en la EIA, los registros ambientales, el acceso a la información ambiental y a otros procedimientos administrativos ambientales que se le incorporan progresivamente a través de una plataforma virtual creada consultada por los usuarios. ${ }^{49}$

Aldana Duran, desde su estudio considera que la VUCA es un mecanismo de gobierno electrónico para el desarrollo de procedimientos de certificación ambiental de la EIA-d, los registros ambientales y otros procedimientos administrativos ambientales que se incorporen. Debe permitir la gestión de la información ambiental relevante en materia de EIA, para adoptar las medidas que correspondan. Se ha aprecia como la VUCA se ha reconocido en los ordenamientos jurídicos en la Ley Marco Ambiental y en la Ley de EIA en Perú, Colombia, Chile, Ecuador, Costa Rica y México en un gobierno digital abierto dentro del Derecho Ambiental Latinoamericano.

La VUCA permite la gestión de la información ambiental en materia de EIA, siendo su nexo vinculante. Su diseño conceptual habrá de formular la arquitectura informática para su implementación adecuada, ello requiere avanzar en diversos frentes de manera integrada para lograr el objetivo de llegar a contar con la herramienta eficiente y que esta se utilice de manera exitosa para alcanzar su fin de mejorar los servicios al ciudadano en materia de otorgamiento de los permisos ambientales por la Autoridad Ambiental en cada Estado. ${ }^{50}$

\footnotetext{
${ }^{47}$ Palomar Olmeda, A. (2008) Gestión electrónica de los procedimientos. La Ley de Administración Electrónica. Comentario sistemático a la Ley 11/2007 de Acceso Electrónico de los Ciudadanos a los Servicios Públicos, Editorial Aranzadi, Cizur Menor; Punzón Moraleda, J. et al. (2009) La utilización de medios electrónicos, informáticos y telemáticos en la Ley 30/2007, de contratos del Sector Público, La Ley, Editorial Las Rozas, España; Sánchez Sánchez, Z. (2009) Administración electrónica y Directiva de Servicios: ¿al servicio del mercado o paradigma de buena administración?, Mercado europeo y reformas administrativas. La transposición de la Directiva de Servicios en España, Editorial Civitas, Navarra.

${ }^{48}$ Font Llovet, T. (1994) Instrumentos jurídicos en la protección del medio ambiente, Revista Aragonesa de Administración Pública, № 5 , España, p. 50; Parejo Alfonso, L. \& Alfonso D. (2012) Autorizaciones y Licencias, Hoy, Editorial Tirant lo Blanch, España; Embid Irujo, A. (2012) La Evaluación de impacto ambiental en la Unión Europea. Revista de Justicia Administrativa. № 57 . España.

${ }^{49}$ Aldana, M. (2016) Caminando hacia la ventanilla única de certificación ambiental, Revista Circulo de Derecho Administrativo, Perú; Comunidad Andina (2016) Implementación de Ventanillas Únicas de Comercio Exterior en los países de la comunidad andina.

${ }^{50}$ Galindo, F. (2006) Gobierno, Derecho y Tecnología: Las actividades de los Poderes Públicos. Editorial Thomson Civitas, España; Manchado, A. (2010) Gobierno abierto: una aproximación desde el Estado. Open Government: Gobierno abierto, Editorial Algón, España; Canals Ametller, D. (2012) Simplificación administrativa y directiva de servicios: objetivos, medios e incidencias, el procedimiento administrativo: descarga burocrática, INAP, España.
} 
Claro está, que con su implementación todos los problemas existentes en la ejecución de la EIA no van a ser resueltos. En todo caso, esta herramienta optimiza el procedimiento administrativo en beneficio del usuario del servicio en beneficio del país que ve la EIA como un medio útil para la prevención de daños ambientales y de los conflictos ambientales que pueda producir. Se realizan procedimientos administrativos en línea mediados por medios electrónicos, cuyos resultados deben contener equivalencia legal a los procedimientos que se realizan en físico, ponderándose el principio de legalidad.

Por su vínculo (VUCA) con los certificados digitales permiten la identificación de una persona a través de un documento electrónico generado y firmado digitalmente por una entidad de certificación con la firma digital, firma que utiliza una técnica de criptografía asimétrica, permite que las personas que conocen la clave pública no puedan derivar de ella la clave privada a los efectos de lograr un procedimiento administrativo con el menor costo posible en términos de tiempo, por ello es recomendable contar con el sistema de pagos del respectivo procedimiento incorporado en el sistema virtual. Para la seguridad de la información es de importancia como objeto de transferencia de información o de pagos de servicios a través del sistema que reduzca la vulnerabilidad ante amenazas que pongan en riesgo la seguridad. ${ }^{51}$ La VUCA tiene nexo la Ley de Firmas y Certificados Digitales, donde todo ciudadano tiene derecho al acceso a servicios públicos para la realización de transacciones de gobierno electrónico con las entidades de la Administración Pública como manifestación de su voluntad, a través de medios electrónicos seguros con el uso de la wifi (cloud). ${ }^{52}$

\subsection{La Ventanilla Única de Certificación Ambiental en Panamá}

En Panamá, el estudio realizado sobre el Derecho Ambiental panameño, se corrobora como desde la carta política hay una protección al medio ambiente, en las leyes de desarrollo aparece desde la Ley General del Ambiente, donde se regula la administración del ambiente como una obligación del Estado y establece los principios y normas básicas para la protección, conservación y recuperación del mismo, promoviendo el uso sostenible de los recursos naturales. Se ordena la gestión ambiental y la integra a los objetivos sociales y económicos, a efecto de lograr el desarrollo humano sostenible.

Se aprecia cómo se reconoce a esta actividad de control a partir del documento público elaborado por la ANAM en la última década del siglo pasado, señala que en las últimas cuatro décadas ha existido una gran preocupación por el entorno ambiental. Se han creado nuevas instituciones y se han adquirido compromisos internacionales y regionales para ofrecerle a los panameños un mejor entorno ambiental. Ponderando retos que van en el orden de una mayor y mejor equidad social,

\footnotetext{
${ }^{51}$ Cruz Rivero, D. (2005) Análisis de los Antecedentes del Concepto de Firma Electrónica como Equivalente a la Firma Manuscrita. Revista de Contratación Electrónica № 60, España; Valenzuela Rivera, M. (2007) Firma digital. Consideraciones jurídicas, Revista Jurídica, Universidad San Carlos, Guatemala.

${ }^{52}$ Delpiazzo C. (2001) Adecuación del Derecho a la necesidad de la firma electrónica, Informática y Derecho: Aportes de doctrina internacional, Editorial Depalma, Buenos Aires.
} 
modernizar la economía, perfeccionar el sistema social, integración del patrimonio nacional, para una visión hasta el 2020 como estrategia para alcanzar el desarrollo sostenible con calidad ambiental. $^{53}$

Desde el punto de vista social, se considera como es necesario integrar a los grupos vulnerables, haciendo énfasis en el papel de la mujer y el medio ambiente, y en la incorporación de los pueblos indígenas como guardianes de importantes espacios territoriales ricos en diversidad biológica y otros recursos naturales como parte de las políticas públicas, algo ya logrado en algunas naciones de América Latina, con el reconocimiento del pluralismo jurídico. De este modo, Panamá ingresa al siglo XXI con graves problemas ambientales que incluyen la destrucción de los recursos forestales y la reducción de la diversidad biológica; la erosión de sus tierras agrícolas, ganaderas y forestales; la contaminación de sus aguas interiores y litorales; la disminución del caudal de los ríos de la vertiente pacífica del istmo, y el crecimiento urbano desordenado que impera sobre todo en la región metropolitana, recocidos por el Ministerio del Ambiente, quien sustituye a la ANAM.

Estos problemas ambientales se valora cómo interactúan con una circunstancia de deterioro social, que es expresada sobre todo en la pobreza que aqueja a cerca de la mitad de la población del país, el crecimiento económico tiende a concentrarse más en los sectores productivos y suelen estar mejor vinculados a la economía mundial, que emplean tecnologías más sofisticadas y generan relativamente poco empleo, como es el caso de la Industria 4.0. ${ }^{54}$

Los estudios realizados en el siglo XXI demuestran que Panamá es uno de los países que muestra desequilibrios en la concentración de la riqueza, del ingreso, de los niveles de educación y salud y de las capacidades que tienen los diferentes grupos de la sociedad para mejorar sus niveles de vida, de aquí que las políticas públicas deberán revertir esta situación adversa. Para solicitar la reparación de daños ambientales desde el plano jurídico, este trámite se ejecuta en la Sala Tercera de lo Contencioso administrativo de la Corte Suprema de Justicia de Panamá en atención al cumplimiento de la Ley General de Ambiente, con referencia al actuar de las Fiscalías especializadas y juzgados que se dedican a la investigación y aplicación de la norma jurídico por la comisión de los delitos ecológicos establecidos en la norma penal. ${ }^{55}$

\section{La gestión ambiental en Panamá dentro de las políticas públicas dentro del gobierno digital}

El Código Ambiental de 2017, establece que el desarrollo territorial de la provincia conlleva la aplicación coherente y eficaz de políticas e instrumentos de gestión económica, social, poblacional, cultural y ambiental, mediante el diseño, desarrollo y ejecución de planes, programas y proyectos

\footnotetext{
${ }^{53}$ Informe ambiental 1999, Autoridad Nacional del Ambiente- Medio Ambiente. Política Ambiental. Panamá.

${ }^{54}$ Estado del ambiente, 2004, Informe del Estado del Ambiente. Geo-Panamá.

${ }^{55}$ Véase para ello, Benavides, V. (2009) Jurisprudencia panameña en materia ambiental, Jornada de Derecho Ambiental y Justicia. Órgano Judicial y la Oficina Regional para América Latina y el Caribe del Programa de Naciones Unidas para el Medio Ambiente, Panamá; Díaz Proll, G. (2011) La Responsabilidad Civil por daños ambientales, Revista Debate. Revista de la Asamblea Nacional de Panamá, N¹8, Panamá; Mitre Guerra, E. (2015) La introducción del principio de no regresión ambiental en la doctrina de la corte suprema de justicia panameña, Universidad Latina de Panamá.
} 
orientados a generar condiciones que permitan su desarrollo, acorde con su dinámica demográfica y espacial, con el Plan Estratégico de Gobierno y los Planes Estratégicos Distritales ejecutados por el Ministerio del Ambiente.

Para ello, los instrumentos para la gestión ambiental son reglamentados y administrados por la Autoridad Ambiental y podrán aplicarse simultáneamente. Los instrumentos que regula la norma son: el ordenamiento ambiental del territorio nacional, evaluaciones ambientales estratégicas, Estudio de Impacto Ambiental. Las inspecciones y auditorías ambientales podrán ser aleatorias o conforme a programas aprobados por el Ministerio del Ambiente y solo podrán ser realizadas por personas naturales o jurídicas debidamente certificadas por la Autoridad Ambiental. El Ministerio del Ambiente a través de la función inspectiva observa el cumplimiento del principio de legalidad. Estos cuerpos jurídicos ponderan la participación ciudadana, ejercida en las Comisiones Consultivas y en los casos en que sea necesaria la opinión de los ciudadanos en la materia ambiental, a partir del principio de información. Lo estudiado demuestra que la gestión ambiental empresarial exige una continua evolución por quienes la ponderan, así como la empresa misma en el entendido como un sistema abierto en perpetuo cambio y adaptación, que puede ser más significativo en lo que al aspecto ambiental se refiere, es el hecho que permite concebir la empresa responsable en la nación al preservar el medio ambiente y los ecosistemas con una adecuada relación ecológica, ello sigue siendo un reto desde las ciencias empresariales, las contables y las ambientales en Panamá.

Con esta interpretación del equipo de auditor en su evaluación ambiental comprobaran los índices de contaminación, el uso de tecnologías limpias, el ahorro de energía y materias primas, la incorporación de la gestión ambiental en los procesos, los riesgos ambientales, la salud humana, y la integridad de los ecosistemas. Es aquí donde se ejecuta la EIA. Por consiguiente, se justiprecia que los estudios realizados antes de esta investigación le preceden desde un enfoque interdisciplinario, lo demuestra el análisis de los valores ambientales realizado en el 2003 en la gestión ambiental. En síntesis, se fija el problema del desempleo como el primero problema en la nación por los encuestados, le continuaron la pobreza, la violencia, la corrupción y el deterioro ambiental fue el penúltimo aspecto. Se deduce entonces que, para la población ante estos problemas, la problemática ambiental todavía puede esperar.

Este estudio demostró que el problema ambiental más importante en términos generales es la contaminación del aire, seguido muy de cerca por la contaminación de los ríos, y la contaminación de la Bahía de Panamá en la gestión ambiental. Conlleva a una reflexión: qué tan responsable se siente el ciudadano de la situación ambiental actual y qué instituciones o empresas están contribuyendo a mejorar el ambiente en Panamá. Los responsables identificados es la empresa 
privada en mayor medida en la ciudad capital y en los demás territorios los gobiernos y el medio ambiente cada vez más se está deteriorando.

Consecuentemente, se considera como los panameños conocen los principales problemas ambientales mundiales. El más conocido por la población es la extinción de las especies animales y vegetales, seguido por la contaminación del aire ocasionado por la industria y el uso de pesticidas y químicos en la agricultura. La Autoridad Ambiental señala que Panamá ha ingresado al siglo XXI con graves problemas ambientales, que incluyen la destrucción de los recursos forestales y la reducción de la diversidad biológica, la erosión de sus tierras agrícolas, ganaderas y forestales; la contaminación de sus aguas interiores y litorales; la disminución del caudal de los ríos de la vertiente pacífica del istmo, y el crecimiento urbano desordenado en la región metropolitana.

Para ello, se valora cómo se establece la enseñanza obligatoria de la Educación Ambiental y la Gestión Integral de Riesgo de Desastres en el sistema educativo en el primer, segundo y tercer nivel de enseñanza, oficiales y particulares, como eje transversal y una estrategia para la conservación, el desarrollo sostenible de los recursos naturales, la protección del ambiente y la prevención ante eventos adversos, mediante métodos alternativos de comunicación, educación, capacitación e investigación. Otra cuestión a revertir, es que las empresas del sector industrial deben desarrollar políticas, procedimientos y formas de trabajo donde se involucren responsablemente todos sus integrantes y utilizar materias primas y procedimientos de producción responsables hacia el medio ambiente, ofrecer productos de calidad y exigir a los proveedores el uso racional de la energía, reducción de residuos, racionalización del consumo de materiales, protección de especies en peligro de extinción, reducción de emisiones, aplicación de tecnologías limpias, y el uso de la etiqueta ambiental. $^{56}$

Muchas empresas del sector industrial de Panamá, afectadas por la presión de la sociedad, el análisis a nivel global y las distintas normas y legislaciones, no visualizan el tratamiento de los impactos ambientales negativos como una opción, sino como una exigencia indispensable para la sostenibilidad y la ubicación ventajosa en los mercados actuales. La integración de la variable ambiental a los sistemas de gestión global ha fluido como un componente decisivo y ha dado lugar a los sistemas de gestión ambiental, hoy en el siglo XXI realizada por empresas privadas. ${ }^{57} \mathrm{La}$ contratación pública para las empresas del sector industrial, aparece como el instrumento eficaz para la consecución de objetivos ambientales dentro de la gestión ambiental. No se trata sólo de que los propios objetivos que motivan la formulación de un contrato tengan que servir para algo más que la

\footnotetext{
${ }^{56}$ Álvarez García, V. (2010) Industria. Derecho de la regulación económica, Editorial lustel, Madrid, pp. 708 y ss.; Pernas García, J. (2013) Libre mercado y protección ambiental; intervención y orientación ambiental de las actividades económicas, Instituto Nacional de Administración Pública, España, pp. 363-364

${ }^{57}$ Pernas García, J. (2004) Estudio jurídico sobre la prevención de la contaminación; la autorización ambiental integrada, Editorial Atelier, Barcelona, p.91; Fortes Martín, A. (2004) El régimen jurídico de la autorización ambiental integrada. Editorial Ecoiuris, Madrid, p.102.
} 
mera producción de bienes o servicios, sino que constituye un instrumento básico para el cambio en el modelo productivo que contribuya a mejorar el medio ambiente, ello es una realidad con el reconocimiento de los permisos negociables -contratación pública verde- ${ }^{58}$ en pos de mitigar la contaminación ambiental. Este tema aún no se pondera de manera adecuada en la nación panameña. También, en el 2017, se realizó otro nuevo estudio sobre el Análisis Ambiental y Social y Plan de Gestión Ambiental y Social para el Programa de Seguridad Hídrica, concluye en significar la necesidad de una mejor calidad del agua, como de tener una actitud proactiva de su uso. Cerramos con el Plan Estratégico Nacional con Visión de Estado "Panamá 2030”, PNUD 2017, el que tiene como objeto hacer realidad los 17 Objetivos de Desarrollo Sostenible, aprobados en las Naciones Unidas y adoptados en la nación de Panamá. ${ }^{59}$

Estos estudios dispusieron que, para garantizar la incorporación constante y permanente de su sostenibilidad económica, social y ambiental, se debe realizar a través de mecanismos de consulta provincial, comarcal y municipal, que tenga un alcance de legitimidad de todas las formas democráticas de interacción sociopolítica en la elaboración y diseño, recolección, ordenamiento, sistematización y análisis de información cuantitativos y cualitativos de los problemas ambientales a través de una gestión ambiental eficiente y eficaz, en ello se pondera el principio de información.

Sobre la VUCA en el gobierno digital en Panamá se aprecia que, dentro de las políticas públicas del gobierno digital, para el tema estudiado aún no existe una respuesta adecuada por la Autoridad Ambiental en el Ministerio del Ambiente, los tramites se hacen de manera física con las instancias que tienen esta competencia. Tan necesarios para agilizar los trámites donde se encuentra involucrado la Administración Pública y los ciudadanos.

\section{Conclusiones}

Las Tecnologías de la Informática y las Comunicaciones han abierto un campo de posibilidades casi ilimitadas para comunicar y compartir la información. La versatilidad de la información digitalizada para su procesamiento (codificación, almacenaje, selección y recuperación) y la posibilidad de su distribución a través de Internet, facilitan enormemente los usos de la información y el conocimiento y, por tanto, las posibilidades de socialización y apropiación cognitiva del acervo informacional y cultural.

\footnotetext{
${ }^{58}$ Véase para profundizar, Montague, S. (2010) Climate Change and Business; Eurostar Environmental Action Plan and its Communication, Real Instituto Elcano, España; Otero García-Castrillón, C. (2010) Incidencia de la protección del medio ambiente en la contratación internacional. Cursos de Derecho Internacional y Relaciones Internacionales de Vitoria- Gasteiz, Editorial de la Universidad del País Vasco, p. 498; Pernas García, J. (2011) Contratación Pública Verde, Editorial La Ley, Madrid, p.70

${ }^{59}$ Agenda 2030 (2018) Los objetivos de desarrollo sostenible. Una oportunidad para América Latina y el Caribe, CEPAL, Chile.
} 
La Ventanilla Única de Certificación Ambiental es un mecanismo en la gestión ambiental. Su fin es simplificar la materialización de la demanda de los diferentes actores involucrados en la emisión de permisos ambientales con el propósito de buscar una mayor racionalización de los trámites y la simplificación de procedimientos que permitan asegurar el objetivo de protección ambiental sin que ello signifique demoras innecesarias o duplicidad de intervenciones de entidades estatales en el proceso requerido para obtener la aprobación de los estudios ambientales u otros permisos ambientales requeridos para el desarrollo de actividades económicas. El gobierno digital constituye una herramienta eficaz para la Administración Pública con el fin de propiciar la participación ciudadana y promover de esta manera la colaboración de la comunidad en función del progreso de un país en beneficio de todos. La participación ciudadana reconocida desde los textos constitucionales establece como un derecho de los ciudadanos para mantener las actividades de control, colaboración e información sobre el Estado actual de su país con transparencia.

Dentro de las políticas públicas para el fomento del gobierno digital en la nación de Panamá, el Ministerio del Ambiente aún no tiene concebido de manera adecuada su implementación para la simplificación de los procesos relacionados con la protección ambiental a través de la Ventanilla Única de Certificación Ambiental.

\section{Referencias bibliográficas}

1. Álamo González, N. (2007) La utilización de las nuevas tecnologías entre las Administraciones públicas y los ciudadanos, REDA, № 133, España.

2. Aldana, M. (2016) Caminando hacia la ventanilla única de certificación ambiental, Revista Circulo de Derecho Administrativo, Perú.

3. Arena, G. (2004) E-Government y Nuevos Modelos de Administración. Revista de Administración Pública No 163 , España.

4. Amoroso Fernández, Y. et al. (2016) Big Data: una herramienta para la Administración Pública, Revista Ciencias de la Información, N. 8, Cuba.

5. Amoroso Fernández, Y. (2014) Gobierno Electrónico: propuesta metodológica de desarrollo y evaluación, UNAM, México.

6. Amoroso Fernández, Y. (2000) Gobierno electrónico. El reto de la gestión y conservación permanente de la información digital, Revista UNAM, México.

7. Amoroso Fernández, Y. (2017) Un acercamiento a la socio-cibernética y la infoética en las Tic: valores éticos y derecho, Revista Argumentos de Razón Técnica, № 20, España, pp.119148 
8. Amoroso Fernández, Y. (2008) Aspectos éticos y legales de la información digital, Facultad de Derecho, Universidad de Valencia, España.

9. Amoroso Fernandez, Y. et al. (2018) Gobierno electrónico: reflexiones desde la UIC. Cibersociedad - soñando y actuando. Editorial Futuro, La Habana, pp.155-171.

10. Antúnez Sánchez, A. (2018) La formación jurídico ambiental mediada por el uso de las Tic, Revista Iberoamericana de bioeconomía y cambio climático, $\mathrm{N}^{\circ} 8$, Nicaragua.

11. Antúnez Sánchez, A. y Sánchez Ramírez, A. (2018) La inspección ambiental. La evaluación de impacto ambiental. La autorización ambiental y la auditoría ambiental, Revista Excelencia Administrativa, $N^{\circ} 38$, México.

12. Agustino y Guilayn, A. et al. (2016) Aspectos legales de las redes sociales, Editorial Bosch, España.

13. Álvarez Caro, M. (2015) Derecho al olvido en Internet: el nuevo paradigma de la privacidad en la era digital, Editorial Reus, España.

14. Barriuso Ruiz, C. (2007) Administración electrónica, Editorial Dykinson, Madrid.

15. Barriuso Ruiz, C. (2002) La contratación electrónica. Editorial Dykinson, Madrid.

16. Blasco Díaz, J. (2008) Los derechos de los ciudadanos en su relación electrónica con la Administración. Derechos fundamentales y otros estudios, Editorial Justicia de Aragón, Zaragoza.

17. Bernadí Gil, X. (2005) Derecho Público y Administración electrónica: una visión panorámica. Nuevas políticas públicas. Anuario multidisciplinar para la modernización de las Administraciones públicas, $N^{\circ} 1$, España.

18. Bergara, M. et al. (2016) Transformaciones económicas en Cuba: una perspectiva institucional, Editorial Universidad de La Habana, Cuba.

19. Beltrán Castellanos, J. (2014) Aproximación al régimen jurídico de las redes sociales, Cuaderno electrónico de estudios jurídicos, $n^{\circ}$. 2, España, pp. 61-90.

20. Cabanellas G. \& Palazzi P. (2004) Derecho de Internet, Editorial Heliasta S.R.L., Argentina.

21. Camacho, G. (2000) Los principios de eficacia y eficiencia administrativas, Editorial Conosur, Argentina.

22. Canals Ametller, D. (2012) Simplificación administrativa y directiva de servicios: objetivos, medios e incidencias, el procedimiento administrativo: descarga burocrática, INAP, España.

23. Castells, M. (2005) La era de la información. La sociedad red, Editorial Alianza, Madrid.

24. Castillo, Y. (2016) Ventanilla única de trámites - Una aproximación conceptual. Monografías-Administración y Finanzas. 
La Ventanilla Única de Certificación Ambiental en Panamá

25. Castoldi, P. (2002) El gobierno electrónico como un nuevo paradigma de Administración. Revista Prudentia Juris, $\mathrm{N}^{\circ} 55$. Buenos Aires.

26. CLAD (2007) Carta Iberoamericana de Gobierno Electrónico. Chile.

27. Cotino Hueso, L. (2006) El Voto Electrónico o la Casa por el Tejado. La Necesidad de Construir la Democracia y Participación Electrónicas por los Cimientos. Libertades, Democracia y Gobierno Electrónicos. Editorial Comares, Granada.

28. Cerrillo Martínez, A. (2007) La Administración Electrónica. Editorial Cizur Menor, Aranzadi.

29. Cerrillo Martínez, A. (2012) La contribución de las Tic a la mejora de la transparencia administrativa. Revista Arbor Ciencia, Pensamiento y Cultura, Vol. 188, España.

30. CEPAL (2007) Libro blanco de interoperabilidad de gobierno electrónico para América Latina y el Caribe. Chile.

31. CEPAL (2018) $6^{\text {ta }}$ Conferencia Ministerial sobre la Sociedad de la Información de América Latina y el Caribe (eLAC2020).

32. CEFACT/ONU (2005) Recomendaciones y Directrices para el Establecimiento de una ventanilla única. United Nations Publications. Ginebra.

33. CEPAL/ONU (2007) Libro Blanco de Interoperabilidad de Gobierno Electrónico para América Latina y el Caribe. Versión 3.0. United Nations Publications. Ginebra.

34. Cierco Seira, C. (2009) Algunas reflexiones sobre la simplificación de los procedimientos administrativos a la luz de los avances de la Administración electrónica, Revista General de Derecho Administrativo, No. 19, España.

35. Cruz Rivero, D. (2005) Análisis de los Antecedentes del Concepto de Firma Electrónica como Equivalente a la Firma Manuscrita. Revista de Contratación Electrónica № 60, España.

36. Cruz Rivero, D. (2006) El DNI Electrónico y el Mercado de las Entidades de Certificación. Revista de Contratación Electrónica. № 69, España.

37. Criado, J. (2009) Gobierno electrónico en Latinoamérica: Aproximación desde una perspectiva intergubernamental, Estado, Gobierno, Gestión Pública. Revista Chilena de Administración Pública, No. 14, Chile.

38. Chéliz Inglés, $\mathrm{M}^{\mathrm{a}}$. (2016) El derecho al olvido digital. Una exigencia de las nuevas tecnologías, recogida en el futuro reglamento general de protección de datos, Actualidad jurídica iberoamericana, $n^{\circ}$. 5, España, pp. 255-271.

39. Delpiazzo C. (2001) Adecuación del Derecho a la necesidad de la firma electrónica, Informática y Derecho: Aportes de doctrina internacional, Editorial Depalma, Buenos Aires. 
40. Delpiazzo, C. (2003) El principio de seguridad jurídica en el mundo virtual, Anuario Derecho Informático, FCU Montevideo.

41. Delpiazzo, C. (2005) Derecho y nuevas tecnologías de la información en los umbrales del siglo XXI, Anuario Derecho Informático, F.C.U. Montevideo.

42. Delgado, T. \& Sánchez Díaz, A. (2018) Repensando el gobierno electrónico: ventanilla única, servicios sostenibles y gobierno digital centrado en la innovación, Revista cubana de Administración Publica y Empresarial, Nº. 3, La Habana.

43. Delgado T. Ramírez Z. \& Amoroso Y. (2018) Hacia un gobierno abierto: necesidad de una política nacional de datos. Cibersociedad - Soñando y Actuando. Editorial Futuro. La Habana, pp. 172-188.

44. Diéguez, G. et al. (2015) Escenarios y perspectivas del gobierno electrónico en América Latina y el Caribe, CIPECC, Buenos Aires.

45. Delgado Novoa, M. (2013) Necesidad de una ley de protección de datos personales en Cuba, Observatorio Iberoamericano de Protección de Datos, España.

46. Holmes, D. (2001) E-Gov, e-Business Strategies for Government. Nicholas Brealy Publisihing, Londres.

47. Hood, C. (2010) Accountability and Transparency: Siamese Twins, Matching Parts, Awkward Couple? West European Politics, No. 5, pp.989-1009.

48. Hernández Ramos, M. (2013) El derecho al olvido digital en la web 2.0. Cuaderno de la cátedra de seguridad salmantina, No $\mathrm{N}^{\circ}$ 11, España, pp. 1-43.

49. Embid Irujo, A. (2012) La Evaluación de impacto ambiental en la Unión Europea. Revista de Justicia Administrativa. N ${ }^{\circ}$ 57. España.

50. Fernández Aller, C. (2012) Algunos retos de la protección de Datos en la sociedad del conocimiento. Especial detenimiento en la computación en nube (cloud computing), Revista de Derecho UNED, No. 10, España.

51. Fernández Esteban, M. (2002) Internet y los derechos fundamentales. Internet, una profecía, Editorial Ariel, España.

52. Font Llovet, T. (1994) Instrumentos jurídicos en la protección del medio ambiente, Revista Aragonesa de Administración Pública, Nº. 5, España, p. 50.

53. Formentín Zayas, Y. (2012) La firma electrónica, su recepción legal. Especial referencia a la ausencia legislativa en Cuba, Revista IUS, №. 31, México.

54. Frosini, V. (1978) Cibernética, Derecho y Sociedad. Editorial Tecnos, Madrid. 
La Ventanilla Única de Certificación Ambiental en Panamá

55. García Rubio, F. (2003) Las nuevas tecnologías ante el Derecho y la organización administrativa. Un estudio sobre las repercusiones en la Administración Local. INAP. España.

56. Garriga Domínguez, A. (2015) Nuevos retos para la protección de datos personales. En la era del big data y de la computación ubicua, Editorial Dykinson, España.

57. Gamero Casado, E. (2008) El procedimiento administrativo electrónico en las entidades locales, con especial referencia al uso de la firma electrónica, Informe sobre la administración electrónica local, Fundació Carles Pi i Sunyer, Barcelona.

58. Gamero Casado, E. (2009) Ventanilla Única y administración electrónica en la transposición de la directiva de servicios, Universidad Pablo de Olavide de Sevilla.

59. Galván Ruiz, J. \& García López, P. (2007) La Administración Electrónica en España. Editorial Ariel, España.

60. Galindo, F. (2006) Gobierno, Derecho y Tecnología: Las actividades de los Poderes Públicos. Editorial Thomson Civitas, España.

61. Gómez Paidós, V. (2006) Sobre las aportaciones y límites de la Red y las redes sociales, para vertebrar nuevas formas de participación cívica en el espacio público, Barcelona.

62. González de la Garza, L. (2008) Voto Electrónico por Internet, Constitución y Riesgos para la Democracia. Editorial Edisofer. España.

63. González, P. (2014) Informe 2014 de Naciones Unidas sobre Gobierno Electrónico.

64. González, C. (2013) Realidad Aumentada. Bubok Publising. United State.

65. Guardián Horta, C. (2010) ¿Transparencia? Open Government: Gobierno abierto, Editorial Algón, España.

66. Manchado, A. (2010) Gobierno abierto: una aproximación desde el Estado. Open Government: Gobierno abierto, Editorial Algón, España.

67. Mate Satué, L. (2016) ¿Qué es realmente el derecho al olvido?, Revista de derecho civil, N. 2, España. pp. 187-222.

68. Martínez Gutiérrez, R. (2009) Administración Pública electrónica, Editorial Civitas, Cizur Menor.

69. Martínez Gutiérrez, R. (2010) Identificación y Autenticación: DNI Electrónico. Administración Electrónica y Ciudadanos. Editorial Civitas Thomson. España.

70. Martínez-Villalva, J. (2014) La cuarta ola de derechos humanos: los derechos digitales, Revista Latinoamericana de Derechos Humanos, México.

71. Martino, A. (2015) Sociocibérnetica, Informática Jurídica e Infoética. Buenas prácticas y Lecciones aprendidas. Editorial UNIJURIS, Cuba. 
72. Meneses Rocha, M. (2015) Ciberutopías. Democracia, redes sociales y movimientos-red. Editorial Porrúa, México.

73. Montesinos, V. (2009) Transparencia y responsabilidad en el sector público: el papel de la información en tiempos de crisis. Revista AECA Nº.87, España, pp.26-28.

74. Martín Delgado, I. (2009) Naturaleza, concepto y régimen jurídico de la actuación administrativa automatizada, RAP, $\mathrm{N}^{\circ}$. 180, España.

75. Morcillo Moreno, J. (2005) La Identidad Digital, mediante el documento nacional de identidad electrónico. Administraciones Públicas y Nuevas Tecnologías. Editorial Lex Nova. España.

76. Mira Ros, C. (2010) El expediente judicial electrónico, Editorial Dykinson, Madrid.

77. Naciones Unidas (2012) Estudio sobre Gobierno Electrónico. Departamento de Economía y Asuntos Sociales. New York.

78. Organización Mundial de Aduanas (2012) Cómo construir un entorno de ventanilla única. Vol. 1. Guía Ejecutiva. OMC.

79. Oliver Cuello, R. (2009) La regulación de la administración electrónica tributaria, Administración Electrónica Tributaria, Editorial Bosch, Barcelona.

80. Ochoa Monzón, J. (200) ¿Hacia la ciberadministración y el ciberprocedimiento? El Derecho Administrativo en el umbral del siglo XXI. Editorial Tirant lo Blanch-Generalitat Valenciana, España.

81. Olivera, N. (2010) Estado de la cuestión de la relación entre Derecho e Informática, Anales, Revista de la Facultad de Ciencias Jurídicas y Sociales de la Universidad Nacional de la Plata, $N^{\circ} 40$, Argentina.

82. Ortiz Chaparro, F. (1995) El Teletrabajo. Una Nueva Sociedad Laboral en la Era de la Tecnología. Editorial McGraw \& Hill. España.

83. Ojeda Bello, Z. et al. (2017) Cuba ante el desafío de asegurar la información personal, Revista Dike, No. 21, Universidad de Puebla, México.

84. Tascón, M. (2013) Big Data: Pasado, presente y futuro. Editorial Telos. España.

85. Téllez Valdés, J. (2004) Derecho Informático, Editorial McGraw Hill, México.

86. Palomar Olmeda, A. (2007) La actividad administrativa efectuada por medios electrónicos, Navarra.

87. Palomar Olmeda, A. (2008) Gestión electrónica de los procedimientos. La Ley de Administración Electrónica. Comentario sistemático a la Ley 11/2007 de Acceso Electrónico de los Ciudadanos a los Servicios Públicos, Editorial Aranzadi, Cizur Menor. 
La Ventanilla Única de Certificación Ambiental en Panamá

88. Parejo Alfonso, L. \& Alfonso D. (2012) Autorizaciones y Licencias, Hoy, Editorial Tirant lo Blanch, España.

89. Paetau, M. (2006) Niklas Luhmann y la Cibernética. Socio-cibernética. Lineamientos de un paradigma, España, pp. 161-192.

90. Piana, R. (2010) La Carta Iberoamericana de Gobierno Electrónico. Orientaciones y buenas prácticas. Democracia Electrónica. Universidad de Zaragoza. España.

91. Piscitelli, A. (2006) Nativos e inmigrantes digitales, ¿Brecha generacional, brecha cognitiva, o las dos juntas y más aún?”, Revista Mexicana de Investigación Educativa, Nº. 28, España. pp.179-185.

92. Pérez Luño, A. (2000) La seguridad jurídica. Boletín de la Facultad de Derecho $\mathrm{N}^{\mathrm{o}}{ }_{15}$, UNED, España.

93. Pérez Luño, A. (2004) ¿Ciberciudadani@o Ciudadani@@.Com?, Editorial Gedisa, Barcelona.

94. Pérez Luño, A. (2006) La tercera generación de derechos humanos, Editorial Thomson Aranzadi, Pamplona.

95. Pérez Luño, A. (2014) Los Derechos Humanos ante las Nuevas Tecnologías. El Tiempo de los Derechos, Editorial Tirant lo Blanch, Valencia.

96. Pérez Luño, A. (2014) Teledemocracia, ciberciudadania y derechos humanos, Revista Brasilera de Políticas Públicas, $N^{\circ} .2$, Brasil.

97. Pérez Luño, A. (2011) Nuevas tecnologías, informática y derechos, Revista Lex, España.

98. Prenski, M. (2010) Nativos e Inmigrantes Digitales, Editorial SEK, España.

99. Piñar Mañas, J. (2007) Revolución tecnológica, Derecho administrativo y Administración pública, La autorización administrativa. La Administración electrónica. La enseñanza del Derecho administrativo hoy, Navarra.

100. Pintos, C. (2012) Open Data, reutilización de la información pública para crear una nueva empresa, Editorial Netbiblo, España.

101. Punzón Moraleda, J. et al. (2009) La utilización de medios electrónicos, informáticos y telemáticos en la Ley 30/2007, de contratos del Sector Público, La Ley, Editorial Las Rozas, España.

102. Plan de Estado para el enfrentamiento del cambio climático (2018) Tarea Vida, Ministerio de Ciencias, Tecnología y Medio Ambiente, La Habana.

103. Platero Alcón, A. (2016) El derecho al olvido en Internet. El fenómeno de los motores de búsqueda, Opinión jurídico, №. 29, Colombia, pp. 243-260.

104. Rivero Ortega, R. (2010) Principio de celeridad, Los principios jurídicos del Derecho Administrativo, Editorial La Ley, Madrid. 
105. Rivero Ortega, R. (2007) El Expediente Administrativo. De los Legajos a los Soportes Electrónicos. Editorial Thomson-Aranzadi. Navarra.

106. Rivero Ortega, R. (2010) Simplificación administrativa y administración electrónica: objetivos pendientes en la transposición de la directiva de servicios, Universidad de Salamanca, España.

107. Ríos, D. (2008) Democracia Electrónica, Editorial LID, Madrid.

108. Robles Morales, J. (2009) Ciudadanía digital: una introducción a un nuevo concepto de ciudadano. Editorial UOC, Barcelona.

109. Rojas Amandi, V. (2000) El Uso de Internet en el Derecho. Oxford University Press, México.

110. Rey Santos O. y Cruz Sardiñas, T (2017) La Ley del Medio Ambiente: 20 años después, Editorial UNIJURIS, La Habana.

111. Rey Santos, O. (2007) Sobre los Instrumentos de la gestión ambiental, Derecho Ambiental Cubano, $2^{\text {da }}$ edición, Editorial Félix Varela, La Habana

112. Real Castro, J. (2018) Portal del ciudadano: una herramienta de gobierno electrónico en Pinar del Río, Taller Internacional las Tic en la Gestión de las Organizaciones, Informática 2018, La Habana.

113. Recio Gayo, M. (2016) Protección de datos personales e innovación: ¿(in)compatibles?, Editorial Reus, España.

114. UNESCO (2013) Enfoques Estratégicos sobre las TICS en América Latina y el Caribe. Oficina Regional de Educación para América Latina y el Caribe, Santiago de Chile.

115. Ugalde, V. (2004) Sobre la digitalización de trámites en la transición al e-gobierno, Revista Gestión y Política Pública, № 1, España, pp. 41-80.

116. Ros, M. (2009) Evolución de los servicios de redes sociales en Internet. Revista el Profesional de la Información, Nº 18 , España.

117. Rossel, P. et al. (2006) Mobile’ E-government Options: Between Technology-driven and User-centric. The Electronic Journal of E-government, №. 2, USA, pp. 79-86.

118. Sáez Vacas, F. (2006) Más allá de la Internet, Revista Isegoría, No 34, España.

119. Sancho Royo, D. (2005) Sociedad de la información y gobierno, Instituto Andaluz de Administración Pública, Sevilla.

120. Salinas, J. (2003) Comunidades virtuales y aprendizaje digital. Revista Edutec, No. 54, España.

121. Sánchez Sánchez, Z. (2009) Administración electrónica y Directiva de Servicios: ¿al servicio del mercado o paradigma de buena administración?, Mercado europeo y reformas 
La Ventanilla Única de Certificación Ambiental en Panamá

administrativas. La transposición de la Directiva de Servicios en España, Editorial Civitas, Navarra.

122. Santamaría Pastor, J. (2009) Principios de Derecho Administrativo, Editorial Iustel, España.

123. Salazar Solís, L. (2006) Ventanilla Única de gobierno electrónico. Colección documentos de trabajo sobre e-Gobierno. Red de Líderes de Gobierno Electrónico de América Latina y El Caribe.

124. Soriano García, J. (2011) El Derecho Administrativo y los desafíos del siglo XXI, Editorial Aranzadi, España. pp. 1-29.

125. Suñe Llinas, E. (2000) Tratado de Derecho Informático. Introducción y Protección de datos personales, $1^{\text {a }}$ edición, Editorial Universidad Complutense de Madrid, España.

126. Suñe Llinas, E. (2016) Derecho informático de las cosas o de segunda generación: El

Derecho de la Informática en la $4^{a}$ Revolución Industrial o de la Productividad, Revista Ambiente Jurídico, №. 19, Colombia.

127. Suñé Llinás, E. (2016) ¿Tres o cuatro generaciones de Derechos Humanos? Aporte de claridad conceptual a una feliz ocurrencia. Los Derechos Humanos en el siglo XXI. Editorial Porrúa, México.

128. Suñé Llinás, E. (2004) La Ventanilla Única Electrónica. Actas del $\mathrm{X}^{\mathrm{o}}$ Congreso Iberoamericano de Derecho e Informática. Centro de Estudios en Derecho Informático, Chile. 129. Suñé Llinás, E. (2016) Prólogo de la publicación Bancos de Datos: pasado, presente y futuro. Universidad Complutense de Madrid, España.

130. Lagares, D. (2000) Internet y el Derecho, Editorial Carena, Barcelona.

131. Lathrop, D. \& Ruma, L. (2010) Open Government. Collaboration, Transparency, and Participation in Practice, Editorial O'Reilly Media. Sebastopol.

132. Lozano Cutanda, B. (2004) Derecho Ambiental Administrativo, $5^{\text {ta }}$ edición, Editorial Dykinson, España.

133. López Menudo, F. (1992) Los principios generales del procedimiento administrativo, Revista de Administración Pública, N 129, España.

134. López Hernández, E. et al. (2016) iLex 1.0: Constitución de la República de Cuba desde su dispositivo móvil, Congreso Internacional de Información, La Habana.

135. López Barrero, E. (2016) La protección de datos e internet: ¿avances o retrocesos?”, Nuevos retos y amenazas a la protección de los derechos humanos en la era de la globalización, Editorial Tirant lo Blanch, España, pp. 95-114. 
136. Luz Clara, B. (2001) Manual de Derecho Informático, Editorial Jurídica Nova Tesis, Argentina.

137. Junceda Moreno, J. (2016) Obligaciones sobre transparencia. Protección de datos. Sobre los límites de la transparencia en el ámbito local. La Administración Práctica, №. 8, España. pp. 55-61.

138. Valero Torrijos, J. (2007) Régimen Jurídico de la e-Administración. El uso de medios informáticos y telemáticos en el procedimiento administrativo, Editorial Comares, Granada.

139. Valero Torrijos, J. (2000) Administración Pública, ciudadanos y nuevas tecnologías. El Derecho Administrativo en el umbral del siglo XXI. Editorial Tirant lo Blanch, Valencia.

140. Valenzuela Rivera, M. (2007) Firma digital. Consideraciones jurídicas, Revista Jurídica, Universidad San Carlos, Guatemala.

141. Vargas, F. (2016) La nueva economía digital, Tribuna del Abogado, №. 197, Montevideo, p. 24 y ss.

142. Villarejo Galende, H. (2008) La simplificación administrativa en la Directiva relativa a los servicios en el mercado interior. Sus repercusiones en la administración electrónica española y el desafío que plantea su transposición, Revista de Derecho de la Unión Europea, $\mathrm{N}^{\mathrm{o}} 14$, España.

143. Welp, Y. (2008) América Latina en la era del gobierno electrónico. Análisis de la introducción de nuevas tecnologías para la mejora de la democracia y el gobierno, Revista Reforma y Democracia. No. 41. España. 